\title{
Plasma Membrane Ultrastructural Differences Between the Exponential and Stationary Phases of Saccharomyces cerevisiae as Revealed by Freeze-Etching
}

\author{
By K. TAKEO \\ Department of Bacteriology, Chest Disease Research Institute, Kyoto University, \\ Sakyo-ku, Kyoto 606, Japan \\ MICHIKO SHIGETA AND Y. TAKAGI \\ Department of Home Science, Osaka University of Education, Jonan, Ikeda 563, Japan
}

(Received I3 May 1976)

\section{SUMMAR Y}

Ultrastructural changes in the plasma membrane of Saccharomyces cerevisiae during the exponential and stationary growth phases were studied by freeze-etching. In the exponential phase, plasma membrane-intercalated particles were distributed randomly. In the stationary phase, several areas of the plasma membrane showed a hexagonal arrangement of particles; these areas appeared to increase with the age of the culture. The polarity of the particles also changed partially: the E-face of the plasma membrane was only sparsely embedded with particles in exponential phase cells, but relatively densely embedded in stationary phase cells. Invaginations of the plasma membrane on the P-face were devoid of particles during both growth phases. Invaginations of the E-face were sparsely embedded with particles in exponential phase cells, but densely embedded with particles in stationary phase cells.

\section{INTRODUCTION}

Use of the freeze-etching technique has revealed two structural components of plasma membranes: protein particles intercalated and randomly distributed in the lipid bilayer continuum (Moor \& Mühlethaler, 1963; Branton, 1966, 1971). Little has been reported on the conformation and arrangement of the lipid molecules, but detailed knowledge of physiological importance has been accumulated through observation of the particles. (i) The density of the particles correlates qualitatively with the metabolic activities of certain types of cells (Scott, Carter \& Kidwell, I97I; Scott \& Marchesi, 1972). (ii) Specialized parts of the plasma membrane, for example ciliary membrane in Tetrahymena, may show specialized shapes and/or distribution pattern of the particles (Sattler \& Staehelin, 1974). (iii) The distribution pattern of the particles may change with the physiological state of the cells, for example, vasopressin-induced changes in the bladder membrane (Kachadorian, Wade \& DiScala, 1975), mucocyst secretion in Tetrahymena (Satir, Schooley \& Satir, 1973), and contact-inhibition-induced aggregation of the particles in cultured mammalian cells (Scott, Furcht \& Kersey, 1973; Furcht \& Scott, 1974, 1975), though the last phenomenon was not confirmed (Pinto da Silva \& Martinez-Palomo, 1975).

Ultrastructural features of the plasma membrane of yeasts have been studied in detail by means of freeze-etching (Moor \& Mühlethaler, 1963; Streiblová, 1968; Matile, Moor \& Robinow, 1969; Nečas, Kopecká \& Brichta, 1969; Bauer, 1970; Takeo et al., 1973). No ultrastructural changes have been reported in the plasma membrane lipids, or the particles, 
during the different growth phases of yeasts, though the number of invaginations increases with the age of the cell.

This paper describes differences in the distribution patterns and polarities of the plasma membrane particles in rapidly growing and stationary phase Saccharomyces cerevisiae.

\section{METHODS}

Organism and growth conditions. Saccharomyces cerevisiae IFOI346 was used for all experiments except that shown in Fig. 4. The organism was grown, with shaking, in Sabouraud medium [ $4 \%(\mathrm{w} / \mathrm{v})$ glucose, $\mathrm{I} \%(\mathrm{w} / \mathrm{v})$ polypeptone] supplemented with $0.2 \%$ yeast extract, usually at $28{ }^{\circ} \mathrm{C}$ but sometimes at $3 \mathrm{I}{ }^{\circ} \mathrm{C}$. Pre-culture medium $(2 \mathrm{ml})$ which had been incubated overnight was inoculated into a culture flask containing $100 \mathrm{ml}$ fresh medium. Growth was followed turbidimetrically at $610 \mathrm{~nm}$. Rapidly growing cells $\left(E_{610} \sim 3\right)$ were used as exponential phase cells. Cultures with an $E_{610}$ of 6 to 9 were used as late exponential phase and early stationary phase cells. Stationary phase cells were obtained by incubating cultures for I to 9 days.

A mixed population of cells was prepared by mixing stationary phase cells, grown for 3 days, harvested, washed twice with fresh medium, and resuspended in fresh medium $\left(E_{610}=2 \cdot 9\right)$, with an equal volume of culture medium in which cells were rapidly growing $\left(E_{610}=2 \cdot 8\right)$. This mixture was incubated for $15 \mathrm{~min}$.

In one experiment, the $\mathrm{pH}$ of the medium (initially at $\mathrm{pH} \mathrm{6.3)} \mathrm{in} \mathrm{which} \mathrm{stationary} \mathrm{phase}$ cells had been grown for 3.5 days was adjusted, by adding I M-NaOH at 15 min intervals during the last $\mathrm{I} \cdot 5 \mathrm{~h}$ of incubation, to maintain the $\mathrm{pH}$ at $5 \cdot 9 \pm 0 \cdot \mathrm{I}$, this being the $\mathrm{pH}$ of the medium during exponential growth.

Preparation of samples for electron microscopy. The yeast was collected by centrifuging ( $1000 \mathrm{~g} ; 3 \mathrm{~min}$; room temperature) and fixed with $2.5 \%$ (w/v) glutaraldehyde in $0.07 \mathrm{M}-$ phosphate buffer $\mathrm{pH} \mathbf{7 \cdot 2}$ for about $2 \mathrm{~h}$ at room temperature. Usually, the yeast was further fixed at $4{ }^{\circ} \mathrm{C}$ for a few days. Before examination, the cells were immersed overnight at $4{ }^{\circ} \mathrm{C}$ in $30 \%(\mathrm{v} / \mathrm{v})$ glycerol in $0.07 \mathrm{M}$-phosphate buffer $\mathrm{pH} 7.2$. Freeze-etching was done as described previously (Takeo et al., 1973). The electron micrographs were printed in reverse to facilitate interpretation.

\section{RESULTS AND DISCUSSION}

The P-face (convex fracture face) of the plasma membrane from Saccharomyces cerevisiae grown to the exponential phase was densely embedded with particles of about $\mathrm{I} 5 \mathrm{~nm}$ diam. at $3 \times 10^{3}$ to $4 \times 10^{3} \mu \mathrm{m}^{-2}$ (Fig. I). These particles were randomly distributed across the entire face. Hexagonal arrangements of the particles were only occasionally observed under our experimental conditions. The few rod-like invaginations of the plasma membrane were short, shallow and devoid of particles. There were only a small number of particles embedded in the E-face (concave fracture face) of the plasma membrane of exponential phase cells (Fig. 2); these were scattered randomly at about $500 \mu \mathrm{m}^{-2}$. The depressions in the plasma membrane lipids left after the particles had been splintered off to the P-side were difficult to observe. Also the invaginations of this fracture face were only sparsely embedded with particles.

The ultrastructural features of plasma membranes from $S$. cerevisiae grown to the stationary phase showed distinct differences from those of the exponential phase cells. Although the P-face of the plasma membrane of yeast cultured for 2 days was also densely embedded with particles (Fig. 3), there were several areas in which particles assumed a hexagonal arrangement, previously reported by Moor \& Mühlethaler (1963). In most cases the hexagonal areas 

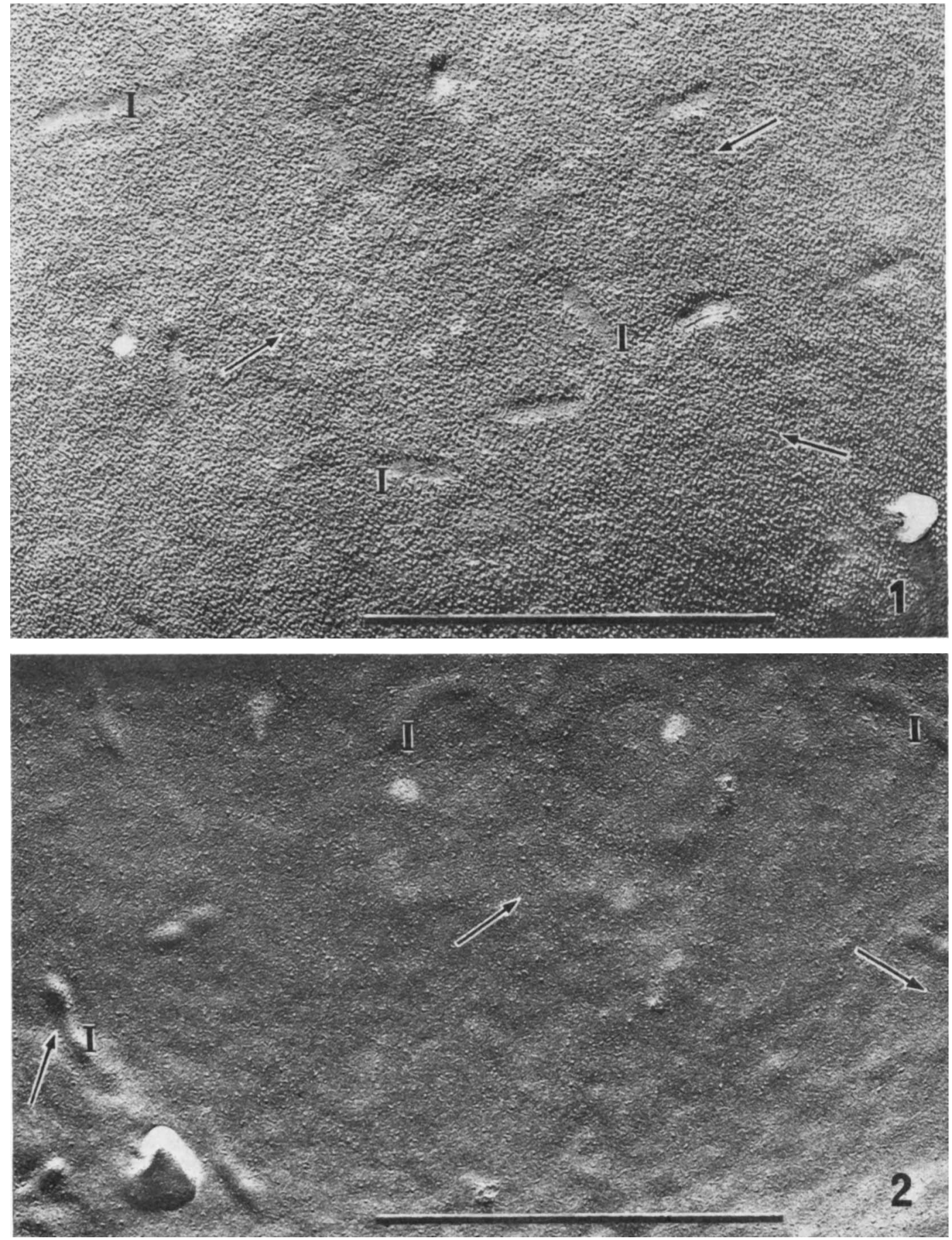

Bar markers represent $\mathrm{I} \mu \mathrm{m}$.

Fig. I. The P-face of the plasma membrane of $S$. cerevisiae in the exponential phase of growth showing randomly distributed particles (arrows) and invaginations (I) which are devoid of particles.

Fig. 2. The E-face of the plasma membrane of $S$. cerevisiae in the exponential phase of growth showing small numbers of particles scattered randomly (arrows). Note also that invaginations (I) are sparsely embedded with particles. 
were slightly depressed. In an extreme case (Fig. 4) the inner part of the wall adjacent to the depressed and hexagonal areas of the membrane appeared smooth, while the outer part of the wall had a particulate appearance. This separation of the membrane in the hexagonal areas from the wall suggests that the hexagonal areas do not have any special affinity with the wall, and that the direct factor or force which produces the hexagonal arrangement of the particles may be in the plasma membrane. In the rest of the plasma membrane the particles were still randomly distributed. The density of the particles was slightly greater (about $I \cdot 5$-fold) in the hexagonal areas than in the other areas, and, as a whole, nearly equalled that in exponential phase cells. The number of invaginations increased and they were deep and somewhat irregular in shape; they were devoid of particles as was the case in exponential phase cells. In old cultures some invaginations were very long.

The E-face of the plasma membrane from stationary phase cells was more densely embedded with particles (about $\mathrm{I} \cdot 3 \times 10^{3} \mu \mathrm{m}^{-2}$ ) than that from exponential phase cells (compare Figs 5 and 2), but less so than the P-face. Furthermore the hexagonal pattern made up by these particles was seen to have many particles absent from the matrix, indicating that more than half of them had split off to the P-side of the plasma membrane during fracturing. The hexagonal areas on the E-face were in most cases slightly raised, corresponding to the depression of these areas on the P-face. There was no significant increase in the density of particles found on the E-face of the plasma membrane in cells incubated for between $I$ and 4 days, but after incubation for 9 days there was a distinct decrease in the density of particles on the E-face. However, the areas of hexagonal arrangement of the particles appeared to increase with culture age. Thus, the polarity of the particles seems to change independently from their distribution pattern. The viability of the cells was also checked: most were viable in cultures incubated for up to 9 days. The polarity of the plasma membrane particles of non-fixed endothelial cells has been reported to be opposite to that of the normal cells, but that it becomes normal on fixation (Dempsey \& Bullivant, 1973). In S. cerevisiae, the change in polarity may be a response to the different growth phases, but it could also be due to other unknown factors.

The distribution pattern of the plasma membrane particles was also studied in late exponential and early stationary phase cells. Some cells scarcely showed the hexagonal arrangement of the particles; others revealed several areas where the particles took on the hexagonal arrangement, though each area was smaller than those seen in plasma membranes of stationary phase cells. This may suggest that the difference in the plasma membrane features between the exponential and stationary phases is not due to subtle differences in the preparation of samples.

The change in the distribution pattern of particles seems to resemble, from the physiological point of view, that of cultured mammalian cells; the plasma membrane particles are

Bar markers represent I $\mu \mathrm{m}$.

Fig. 3. The P-face of the plasma membrane of $S$. cerevisiae in the stationary phase of growth (2-day culture) showing several areas where particles are in a hexagonal arrangement (arrows). The hexagonal areas are usually slightly depressed. Invaginations (I) are devoid of particles.

Fig. 4. Saccharomycodes ludwigii plasma membrane showing an extreme case of a separation of the plasma membrane from the wall (W). The separation is distinct where particles are in a hexagonal arrangement (arrows); this is also observed, but to a lesser extent, in $S$. cerevisiae.

Fig. 5. The E-face of the plasma membrane of $S$. cerevisiae in the stationary phase of growth (2-day culture). Particles are much denser than in the exponential phase cells (compare with Fig. 2). Note also several slightly raised areas where particles are in a hexagonal arrangement (arrows). Invaginations (I) are densely embedded with particles. 

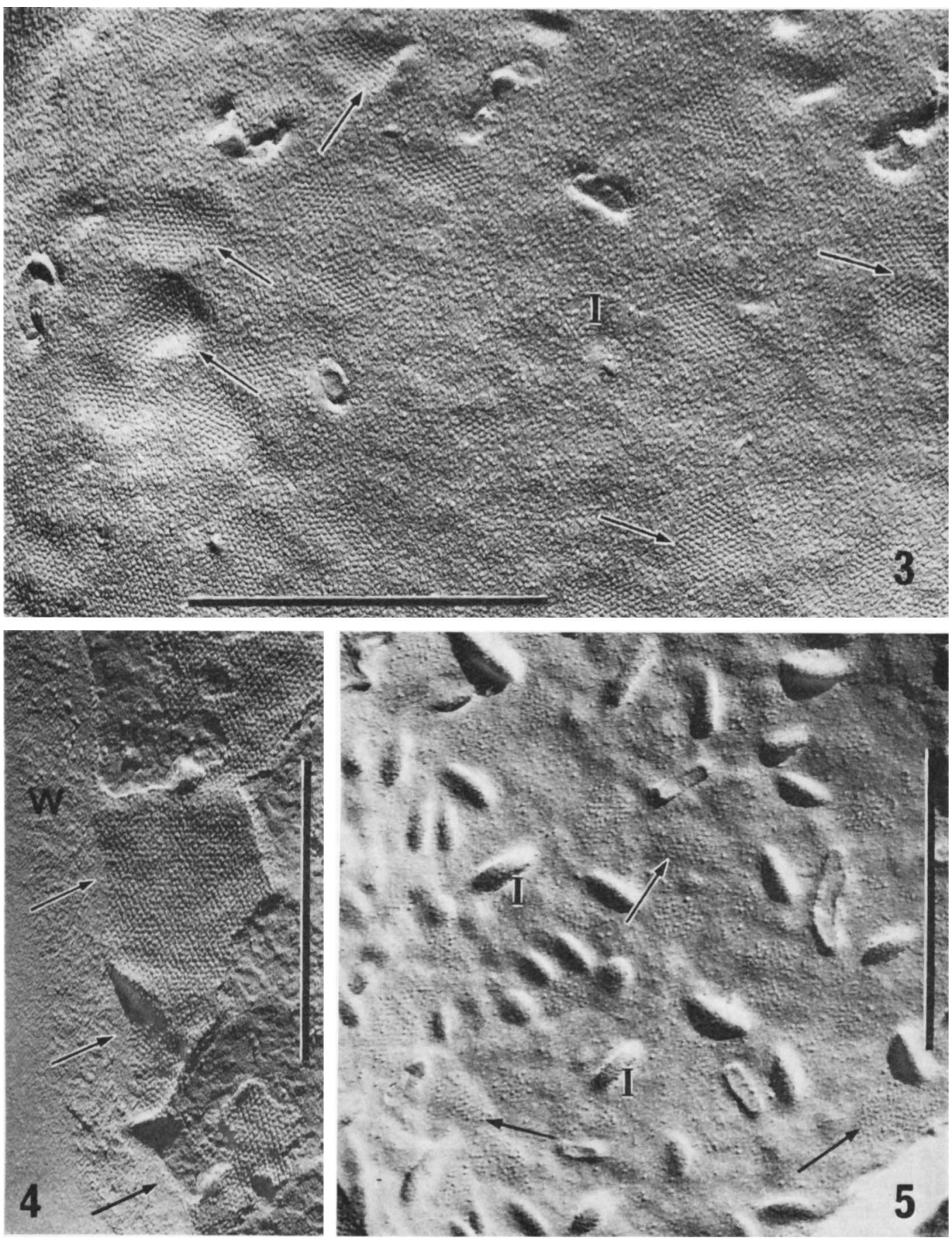
randomly distributed when the cells are growing but are aggregated when the cells are contact-inhibited. These phenomena were first reported by Scott $e$ t al. (1973) and again by Furcht \& Scott $(1974,1975)$ but were not confirmed by Pinto da Silva \& Martinez-Palomo (1975). Thus subtle experimental changes may cause distinct differences in results. To minimize such changes exponential and stationary phase cultures were prepared in pairs, and the cells were collected and fixed simultaneously. In addition, stationary phase cells were mixed with the exponential phase cells, and cultured for $15 \mathrm{~min}$. In both cases, the same two types of membrane as hitherto described were recognized, although in the latter case the areas showing the hexagonal arrangement of the particles had decreased considerably.

Several treatments have been reported to cause aggregation or redistribution of plasma membrane particles. Some seem to be involved in a specific cell type, such as the particle redistribution in the bladder membrane elicited by vasopressin (Kachadorian et al., 1975). Others are more physicochemical treatments: lowering the pH (Pinto da Silva, 1972); lowering the temperature (Haest et al., 1974); cryoprotectant treatment (McIntyre, Gilula \& Karnovsky, 1974); and incubation in phosphate-buffered saline (Pinto da Silva \& MartinezPalomo, 1975). In view of these observations, the fall in the $\mathrm{pH}$ of the stationary phase culture medium might possibly cause the change in distribution pattern observed in $S$. cerevisiae during the different growth phases. However, this possibility is considered unlikely because the typical hexagonal arrangement of particles in plasma membranes from stationary phase cells was still seen when the stationary phase cells were held in the same medium as the exponential phase cells (see above), and when the $\mathrm{pH}$ of the medium containing the stationary phase cells was adjusted to $\mathrm{pH}_{5.9}$ (the $\mathrm{pH}$ of the medium during exponential growth). Thus the $\mathrm{pH}$ change of the external medium is probably not a principle cause of the hexagonal distribution of particles though the fall in the $\mathrm{pH}$ inside the stationary phase cells might be a cause.

A characteristic feature of the yeast plasma membrane is the existence of invaginations, but their physiological role is not clear. Nečas et al. (1969) showed that the invaginations on the E-face were densely particulate and suggested that the particles were preferentially bound to the P-face of the entire plasma membrane except in the invaginations where the polarity of the particles was reversed. Our results show that this is true only of cells which are in the stationary phase. In exponential phase cells, the invaginations are almost entirely devoid of particles, on both the P- and E-faces. As the plasma membrane lipids are a fluid in which the particles may move relatively freely (Singer \& Nicolson, 1972), the invaginations probably have a special mechanism which inhibits the entrance of the particles, e.g. by accumulation of certain kinds of lipids which solidify at the growth temperature and squeeze out the protein particles. As protein in the membrane seems to exist predominantly in the form of particles, the metabolic activities in the invaginations in exponential phase cells are expected to be low.

The density of the plasma membrane-intercalated particles in stationary phase $S$. cerevisiae is no less than that in exponential phase cells; Bauer (1969) has reported similar results in Wickerhamia fluorescens. No correlation of particle density and metabolic activities was observed in these yeasts although it has been reported in phytohaemagglutinin-stimulated lymphocytes (Scott \& Marchesi, 1972). Other methods have suggested that the activities of the plasma membrane in stationary phase $S$. cerevisiae are inhibited. The hexagonal arrangement of the particles may be a reflection of the inhibitory mechanism of the plasma membrane activities (see also Takeo, 1976).

We thank Professor I. Uesaka for his interest and Mrs E. Yamagishi for technical assistance. 


\section{REFERENCES}

BAUER, H. (1970). A freeze-etch study of membranes in the yeast Wickerhamia fluorescens. Canadian Journal of Microbiology 16, 219-222.

Branton, D. (1966). Fracture faces of frozen membranes. Proceedings of the National Academy of Sciences of the United States of America 55, 1048-1056.

Branton, D. (1971). Freeze-etching studies of membrane structure. Philosophical Transactions of the Royal Society of London B 261, 133-138.

DemPSeY, G. P. \& Bullivant, S. (1973). Endothelial cell membrane: polarity of particles as seen by freezefracturing. Science 179, 190-192.

Furcht, L. T. \& Scotr, R. E. (1974). Influence of cell cycle and cell movement on the distribution of intermembranous particles in contact-inhibited and transformed cells. Experimental Cell Research 88, 3II-3I8.

FURCHT, L. T. \& SCOTT, R. E. (1975). Modulation of the distribution of plasma membrane intramembranous particles in contact-inhibited and transformed cells. Biochimica et biophysica acta 401, 213-220.

Haest, C. W. M., Verkleit, A. J., De Gier, J., Scheek, R., Ververgaert, P. H. J. \& Van Deenen, L. L. M. (1974). The effect of lipid phase transitions on the architecture of bacterial membranes. Biochimica et biophysica acta 356, 17-26.

KaChadorian, W. A., Wade, J. B. \& DiScala, V. A. (1975). Vasopressin-induced structural change in toad bladder luminal membrane. Science 190, 67-69.

MCINTYRE, J. A., Gilula, N. B. \& KaRnovsky, M. J. (I974). Cryoprotectant-induced redistribution of intramembranous particles in mouse lymphocytes. Journal of Cell Biology 60, 192-203.

Matile, Ph., Moor, H. \& Robinow, C. F. (I969). Yeast cytology. In The Yeasts, vol. 1, pp. $219-302$. Edited by A. H. Rose and J. S. Harrison. London and New York: Academic Press.

MOOR, H. \& MüHLethaleR, K. (1963). Fine structure in frozen-etched yeast cells. Journal of Cell Biology I7, $609-628$.

NEČAS, O., KOPECKÁ, M. \& BRICHTA, J. (1969). Interpretation of surface structures in frozen-etched protoplasts of yeasts. Experimental Cell Research 58, 4I I-4I9.

Pinto DA Silva, P. (1972). Translational mobility of the membrane intercalated particles of human erythrocyte ghosts. pH-dependent, reversible aggregation. Journal of Cell Biology 53, 777-787.

Pinto Da Silva, P. \& Martinez-Palomo, A. (1975). Distribution of membrane particles and gap junctions in normal and transformed $3 \mathrm{~T}_{3}$ cells studied in situ, in suspension, and treated with concanavalin $A$. Proceedings of the National Academy of Sciences of the United States of America 72, 572-576.

SATIR, B., Schooley, C. \& SATIR, P. (1973). Membrane fusion in a model system. Mucocyst secretion in Tetrahymena. Journal of Cell Biology 56, 153-176.

SATtler, C. A. \& Staehelin, L. A. (1974). Ciliary membrane differentiations in Tetrahymena pyriformis. Tetrahymena has four types of cilia. Journal of Cell Biology 62, 473-490.

SCOTT, R. E. \& MARCHESI, V.T. (1972). Structural changes in membranes of transformed lymphocytes demonstrated by freeze-etching. Cellular Immunology 3, 30r-3I 7.

SCOTT, R. E., CARTER, R. L. \& KIDWELl, W. R. (1971). Structural changes in membranes of synchronized cells demonstrated by freeze-cleavage. Nature New Biology 233, 219-220.

SCOTT, R. E., FuRCHT, L. T. \& KERSEY, J. H. (1973). Changes in membrane structure associated with cell contact. Proceedings of the National Academy of Sciences of the United States of America 70, 3631-3635.

Singer, S. J. \& Nicolson, G. L. (1972). The fluid mosaic model of the structure of cell membranes. Science I75, 720-731.

STREIBLOVÁ, E. (1968). Surface structure of yeast protoplasts. Journal of Bacteriology 95, 700-707.

TAKEO, K. (1976). Ultrastructural features underlying the hexagonal arrangement of plasma membraneintercalated particles of Saccharomyces cerevisiae. Journal of General Microbiology 97, 33 I-334.

TAKEO, K., Uesaka, I., UeHIRA, K. \& NishIURA, M. (1973). Fine structure of Cryptococcus neoformans grown in vitro as observed by freeze-etching. Journal of Bacteriology II3, 1442-1448. 